\title{
Kenya: Helping adolescent mothers remain in school through strengthened implementation of school re-entry policies
}

\author{
Esther Lwanga Walgwe \\ Population Council \\ Nancy Termini LaChance \\ Population Council \\ Harriet Birungi \\ Population Council \\ Chi-Chi Undie \\ Population Council
}

Follow this and additional works at: https://knowledgecommons.popcouncil.org/departments_sbsr-rh

Part of the Demography, Population, and Ecology Commons, Family, Life Course, and Society Commons, Gender and Sexuality Commons, International Public Health Commons, Maternal and Child Health Commons, Public Health Education and Promotion Commons, and the Women's Health Commons How does access to this work benefit you? Let us know!

\section{Recommended Citation}

Walgwe, Esther Lwanga, Nancy Termini LaChance, Harriet Birungi, and Chi-Chi Undie. 2016. "Kenya: Helping adolescent mothers remain in school through strengthened implementation of school re-entry policies," STEP UP Case Study. Nairobi: Population Council. 


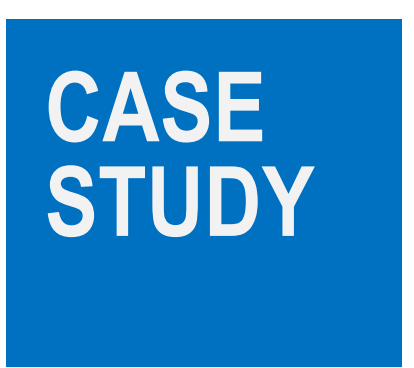

NOVEMBER 2016
STEP UP generates policy-relevant research to promote an evidencebased approach for improving access to family planning and safe abortion.

We work in Bangladesh, northern India, Ghana, Kenya, and Senegal.

Population Council Coordinating Partner

African Population and Health Research Center icddr.b

London School of Hygiene and Tropical Medicine

Marie Stopes International

Partners in Population and Development

Funded by

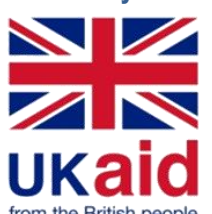

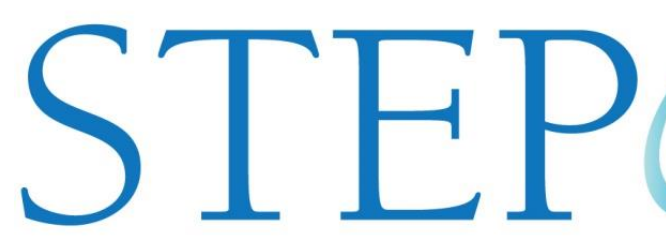

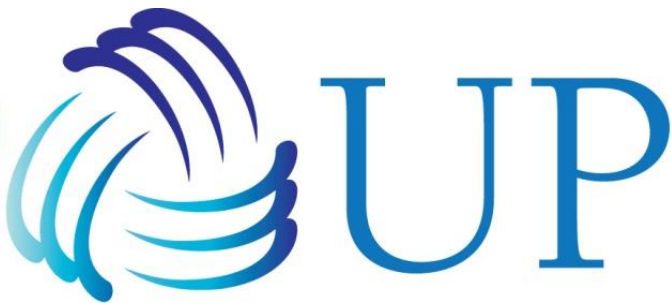

STRENGTHENING EVIDENCE FOR PROGRAMMING ON UNINTENDED PREGNANCY

\section{FROM EVIDENCE TO IMPACT: A look at how STEP UP}

\section{research was used to impact policies and programmes}

The goal of family planning and reproductive health operations research is to generate evidence that helps policies and programmes maximize access to and quality of services for women and their families. Yet the crucial step of ensuring the utilization of that evidence often receives inconsistent or inadequate attention. There is relatively little monitoring and reporting on whether and to what effect project results are utilized, or on the nature, process, and efficacy of the strategies employed to achieve this.

The goal of this case study is to document an activity of the STEP UP research programme consortium which resulted in successful evidence utilization. This is to both demonstrate the positive impact STEP UP is having on family planning and reproductive health policies, as well as to document the process by which this was achieved so as to inform future research of successful strategies and lessons learned.

\section{SUMMARY}

By applying robust evidence, securing the support of decision makers, and engaging stakeholders, STEP UP enabled national and local decision makers to better understand the consequences of unintended pregnancy for adolescent girls' schooling in Homa Bay County, Kenya. Through this and subsequent research uptake, STEP UP has successfully contributed to several impacts that include:

- A reversal of attitudes of school principals, students, decision makers, and community members away from traditional negative perceptions of teenage pregnancy and towards one of understanding and support

- An increase in the proportion of out-of-school girls re-entering school

- Multiple local innovations to support re-entry

- Generation of evidence that provided a basis for the drafting of a new parliamentary bill to support girls' re-entry into school

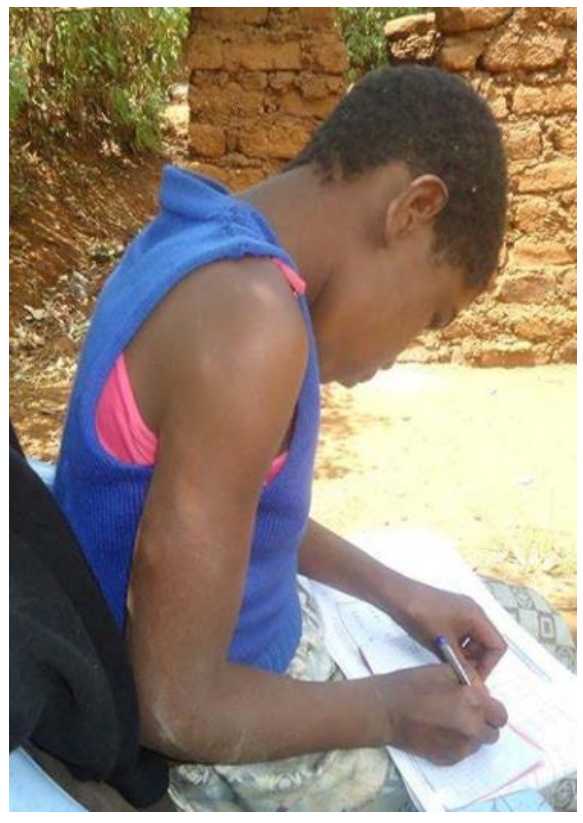

Photo courtesy of Uwezo Kenya

- Improvement of national school re-entry guidelines 


\section{INTRODUCTION}

In Kenya, early and unintended pregnancy is a pivotal event in the lives of adolescent girls, and presents a huge and cross-cutting challenge to both their education and their sexual and reproductive health. Pregnancy very often means the end of education for girls (though rarely for the boys who become teenage parents). Once pregnant, the economic potential of girls is further limited by their low educational attainment and the increased possibility of early marriage. ${ }^{1}$ Poverty, limited knowledge of contraception, and a lack of independence with regard to life choices make this population especially vulnerable.

Although Kenya's national school health policy states that school-age girls who become pregnant should be permitted to continue with their education for as long as possible and allowed to return to school after childbirth, implementation of this policy remains weak in practice. Furthermore, there are limited proven interventions to increase demand for education among out-of-school teenage mothers or to address unintended pregnancy among this group. ${ }^{2}$

Homa Bay County in Kenya experiences these trends acutely; it has the second highest levels of teenage childbearing in the country (at 33\%) and is characterized by high unintended teenage pregnancy and female school drop-out rates. The primary school completion rate for girls in Homa Bay County is only $54 \%$. In addition, an estimated $48 \%$ of girls in the county are out of school, and $40 \%$ of girls aged $15-19$ have begun childbearing. ${ }^{5}$

\section{THE PROJECT}

In light of this situation in Homa Bay, STEP UP sought to:

1) Foster an understanding of the context surrounding outof-school mothers and their potential school re-entry support systems in school and at home, and provide a benchmark against which progress of re-entry promotion efforts may be measured;

2) Identify possible interventions to promote re-entry;

3) Increase demand for secondary school education among teenage mothers through enhanced awareness of existing school re-entry policies for pregnant and parenting students within Homa Bay County. This effort was underpinned by Kenya's national school health policy, which permits pregnant students to remain in school for as long as possible, and Kenya's school re-entry policy, which encourages re-entry after childbirth.
In Kenya:

\section{8\% of girls who have ever been pregnant are out of school ${ }^{4}$}

\section{$59 \%$ of pregnancies among girls aged 15-19 years are unintended ${ }^{4}$ \\ $45 \%$ of severe abortion complications are among adolescent girls ${ }^{4}$}

This project included an interactive media campaign that targeted schools and communities; evidence-based advocacy to promote policy implementation; and two policy dialogues held with an estimated 200 Homa Bay County school principals and other education decision makers. Baseline data was gathered using household surveys in 2 sub-counties (with both out-of-school girls and their heads of household), and secondary school surveys (which included 1,413 students and 167 school principals.) These activities were developed in partnership with the Homa Bay County Department of Education.

\section{KEY STUDY RESULTS}

\section{Factors in dropping out early and barriers to re-entry}

- Pregnancy is often the critical incident that precedes school dropout by teenage mothers; among out-ofschool girls aged 13-19, pregnancy was the main reason (66\%) for dropping out of school.

- For the vast majority of these schoolgirls - married or unmarried - pregnancy was unintended (93\%).

- $83 \%$ of students indicated that their schools do not provide information on contraception.

- Financial restraints resulting from pregnancy (including childcare costs) are key barriers to school re-entry.

- Unintended pregnancy (UP) often precipitates early marriage; one third of the teenage mothers surveyed were married, and of these, $92 \%$ married due to the pregnancy.

- Most out-of-school teenage mothers would like to go back to school someday.

\section{Community-level factors}

- Community attitudes toward school continuation by pregnant learners or re-entry by parenting students are largely positive; however, awareness of school policies regarding pregnant and parenting students is limited and needs to be enhanced. 
- Radio is an important means of conveying policy information to students, teen mothers, and heads of household in Homa Bay.

The policy dialogues, convened with the Homa Bay County Department of Education, fostered awareness of school re-entry policies and revealed the attitudes of principals and education decision makers towards student UP. The first dialogue, held in August 2014, revealed that:

- There was a generally negative attitude towards student pregnancy.

- Participants were concerned about the challenge of repeat pregnancies; it was perceived that if girls had a repeat pregnancy, promoting their re-entry into the school system would be a pointless effort.

- Expulsion was viewed as acceptable as both a disciplinary measure and a deterrent to other girls becoming pregnant.

- School reputations were perceived to suffer as a result of pregnant students; it was assumed that they perform poorly and lower the schools' 'Mean Grade.' Further, principals reported that their own professional reputations were at risk if they were seen to support perceived immorality.

- Many principals had never seen copies of the re-entry policies. Those who were aware of them had learned about them through work-related structures.

The second policy dialogue, held in April 2016, shared evidence from the study with the same stakeholders. This dialogue revealed a marked difference in their attitudes:

- There was a notable positive shift in tone away from the previously stated views of adolescent UP in the first meeting.

- Many participants emphasized how valuable the presentation of data was to their changed opinions.

- Many participants cited success stories of girls who re-entered school, proved to be diligent students, and did well academically when given support.

\footnotetext{
"The data has spoken to us" --Honorable Peter Kaluma, Member of Parliament Homa Bay County
}

"Pregnancy is not a disability... (school) re-entry is a right, it is not a privilege"

--Mrs. Ahindukha, Homa Bay County Dep't of Education Teachers Service Commission Director

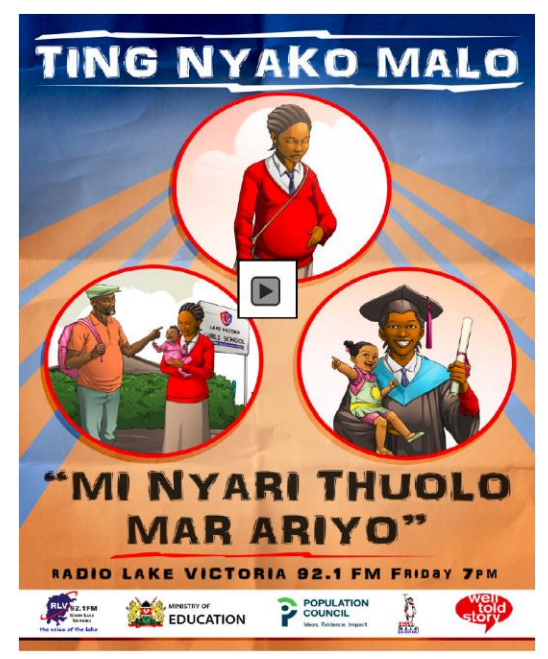

\section{MAKING AN IMPACT}

\section{Influence on policy and programme improvements}

\section{Drafting of a new parliamentary bill defending} pregnant schoolgirls and their right to re-entry Entitled, "The Care and Protection of Child Parents Bill, 2016," this bill would forbid schools from expelling students who become pregnant, disallow compulsory pregnancy tests, and would require schools to ensure harassment-free environments for student parents. Further, county governments would be required to build and maintain childcare centres to support student parents. The work of several partners, including STEP UP, was integral to drawing attention to and improving understanding of the issue of unintended pregnancy among schoolgirls, leading to this draft bill.

\section{Widespread change in attitudes and behaviour of community regarding school re-entry}

As a result of the policy dialogues and the interactive media campaign, significant positive changes surrounding re-entry knowledge, attitudes, and practices were witnessed in the community (including among out-of-school girls, household heads, principals, and other students). There was a significant increase in the proportion of out-of-school girls who re-entered school - from $10 \%$ at baseline to $16 \%$ at endline.

Participants agreed that there is a need for clearer guidelines on the implementation of the school re-entry policies. The resounding feedback was that teenage mothers can, and should, be encouraged to return to school and that there is also a need for more effective pregnancy prevention programs within schools. 
Improvement of national school re-entry guidelines The Ministry of Education decided to convene a meeting in December 2016 to develop improved school re-entry guidelines (in collaboration with UNFPA and UNESCO). STEP UP, having contributed to raising awareness and generating evidence surrounding this issue, was invited to participate in this effort.

\section{Establishment of local innovations to support school re-entry}

During the project period, the Homa Bay County Department of Education independently decided to document and track the re-entry of out of school girls in all primary and secondary schools in the entire County so as to ensure that re-entry was occurring, and that principals were promoting this process.

In addition, in July 2016, the Homa Bay County Department of Education also institutionalized and awarded a prize for the top two primary and secondary schools in the county that had shown massive support for girls' school re-entry.

\section{Who will benefit?}

- Adolescent girls: The vast majority of girls who leave school due to unintended pregnancy want to return to school. Completing their education correlates with higher wages and gives girls choices and opportunities that would otherwise be lost to them, helping to break the cycle of poverty. Furthermore, educated girls are less likely to marry early and against their will and are less likely to die in childbirth. ${ }^{3}$

- Families: When a girl is educated, it benefits her entire family: educated girls can earn better livings and thus can better support their families; are more likely to have healthy babies; and are more likely to send their own children to school. ${ }^{3}$

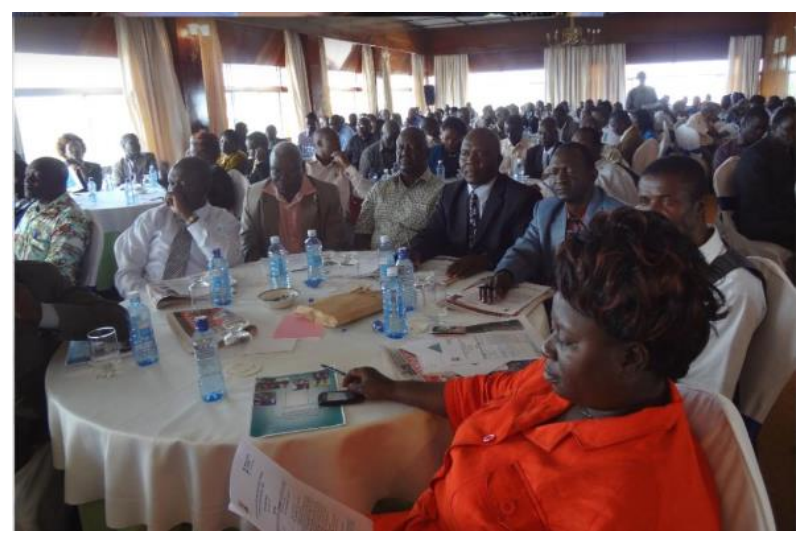

HOW WAS IMPACT ACHIEVED? SOME KEY LESSONS LEARNED

\section{Effective strategies for communication and dissemination}

In collaboration with Well Told Story - an Emmy award-winning communication research and productions company in Kenya - the project team developed their communications and dissemination strategy with a substantial focus on the local and national socio-cultural context. Further, baseline data included an assessment of the main media sources of information (for teenage mothers, heads of household, and policymakers), when they accessed them, and with whom. This impacted how key messages were framed and what modes of communication were used (e.g. radio ads were aired at times when teenage mothers and household heads were most likely to be listening.)

The policy dialogue mechanism was a valuable way to accurately convey the evidence to multiple levels of decision makers - county governments and principals - through work-related structures. Participants were able to understand the content of, and rationale for, the policies, deliberate in an open forum, and contribute to collective solution creation.

The critical importance of dialogue Involving school principals so centrally in the intervention through dialogues revealed the complexity of their perspectives, the range of constraints they faced, and their overall desire to help their students receive education. By recognizing that schools are an ally - not an enemy - in the process of building support for pregnant schoolgirls, STEP UP was able to support the development of constructive interventions that addressed actual barriers to policy implementation. The policy dialogues enabled open, honest discussions that fostered listening, asked tough questions, and built towards breakthroughs in thinking.

\section{Engaging key stakeholders and establishing support early}

The Homa Bay County Department of Education (and through it, the Ministry of Education) were a part of the project design and intervention planning from the initiation of the project. This both enabled project 
activities to be relevant and appropriate, as well as laid some of the groundwork for the subsequent awareness, support, and positive reception of these messages by government stakeholders.

In addition, STEP UP was able to gain and maintain momentum and the active engagement of key stakeholders by working with several Senior County Government personnel across agencies, thus avoiding delays in evidence uptake that can arise from changes in leadership and competing political priorities.

\section{Robust research on an issue of existing community concern}

It was clear to participants in the policy dialogues that the project's evidence did not exist in a vacuum; STEP UP and the Homa Bay County Department of Education had identified an issue of strong interest and relevance. Participants' inclination to compare the evidence presented with their own contexts was borne out, as the spectrum of data fully reflected their anecdotal experiences. The fact that the evidence presented was generated using robust methods, conveyed an array of relevant factors, and involved surveys with multiple levels of stakeholders reinforced the quality and reliability of the data for participants.

\section{Existing capacity of decision makers}

While the national policies existed to support schooling of pregnant adolescents, their implementation was poor. Yet once STEP UP engaged key stakeholders to build their knowledge on the core aspects of these policies and the real-life impact of pregnancy on the lives of adolescent girls (backed up by evidence), participants displayed the capacity to effectively incorporate it to their contexts.

"Thank you abundantly for the wonderfully-conducted dialogue... The exposure has opened up my eyes at both a personal and administrative level and things will never be the same again for all kinds of vulnerabilities in the school set-up."

-- School principal at second policy dialogue

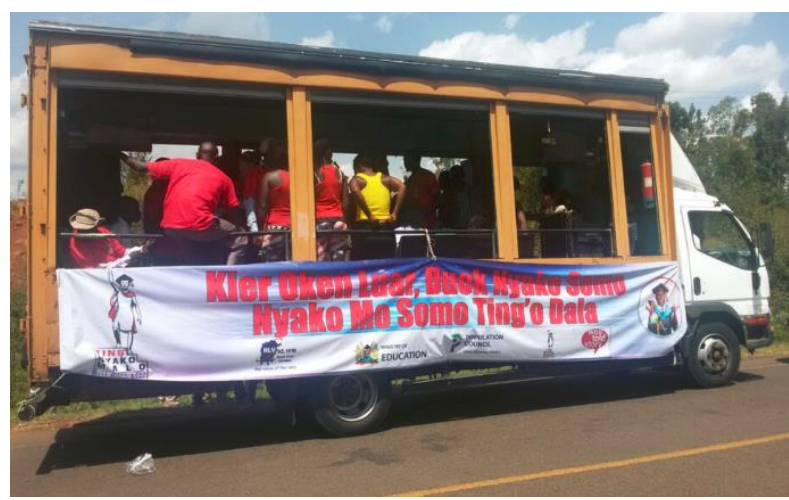

\section{CONCLUSION}

STEP UP is playing an important role in informing the implementation of policies within the Kenyan educational sector that will improve educational opportunities for school-age mothers. Through early stakeholder engagement, strong partnerships, the support of implementers and policymakers, effective communications and dissemination strategies, decision maker capacity, and the dedication of the adolescent mothers themselves, evidence generated by STEP UP was successfully utilized by key stakeholders. Through this work, STEP UP has seen a positive shift in the discourse among Homa Bay County stakeholders on the continued education of all girls and the development of culturally appropriate models to better address UP in this population.

\section{REFERENCES AND SUGGESTED READINGS:}

1. Improving Reproductive, Maternal, and Newborn Health: Reducing Unintended Pregnancies. DFID Evidence Review. 2010.

2. Undie C, Birungi H, Odwe G. and Obare F. 2015. "Expanding Access to Secondary School Education for Teenage Mothers in Kenya: A Baseline Study Report," STEP UP Technical Report. Nairobi.

3. Promoting Gender Equality through UNICEF-Supported Programming in Basic Education. New York: UNICEF.

4. Kenya National Bureau of Statistics, Ministry of Health, National AIDS Control Council, Kenya Medical Research Institute, National Council for Population and Development, ICF International. 2015. Kenya Demographic and Health Survey 2014. Calverton, Maryland: KNBS, MOH, NACC, KEMRI, NCPD, and ICF International.

5. Kenya National Bureau of Statistics. 2013. Homa Bay County Multiple Indicator Cluster Survey 2011, Final Report. Nairobi: Kenya National Bureau of Statistics.

\footnotetext{
Suggested citation:

Walgwe, E.L., Termini, N., Birungi, H., Undie, C. 2016. "KENYA: Helping adolescent mothers remain in school through strengthened implementation of school re-entry policy," STEP UP Case Study, November 2016. Nairobi: Population Council.
} 